\title{
Nível de satisfação no trabalho em propriedades rurais: estudo de caso em Rio Brilhante, Mato Grosso do Sul, Brasil
}

\section{Level of job satisfaction in rural properties: a case study in Rio Brilhante, Mato Grosso do Sul, Brazil}

\author{
Sulma Vanessa Souza ${ }^{1}$ \\ Luanne Escobar do Nascimento Oliveira ${ }^{2}$ \\ Marcel Gonçalves de Almeida ${ }^{3}$ \\ Omar Jorge Sabbag ${ }^{4}$
}

\section{Resumo}

O tema satisfação no trabalho tornou-se, no decorrer dos anos, objeto de vários estudos; isso ocorreu, sobretudo, pela necessidade da valorização do trabalhador nas organizações, uma vez que a satisfação ou insatisfação influi diretamente no sucesso de qualquer organização. Diante disso, objetivou-se analisar o nível de satisfação no trabalho em propriedades rurais localizadas no município de Rio Brilhante/MS. Para a coleta de dados, utilizou-se um questionário estruturado, desenvolvido de acordo com a escala multidimensional EST-Reduzida. Os resultados constataram de modo unânime um padrão de nível de satisfação para ambas as propriedades. Entretanto, verificou-se que a propriedade A apresentou o menor escore médio na dimensão 1 - Satisfação com os colegas $(4,62)$, assim como a propriedade B, na dimensão 3 - Satisfação com a chefia $(4,83)$, sendo pertinente aos gestores criarem medidas mitigadoras para a sua correção, haja vista tais resultados serem fatores que poderão prejudicar o desempenho das propriedades

Palavras-Chaves: Satisfação no trabalho. Desempenho. Escala EST.

\begin{abstract}
The topic of job satisfaction has become, over the years, the object of several studies; this was mainly due to the need to value the worker in organizations, since satisfaction or dissatisfaction directly influences the success of any organization. Therefore, the objective was to analyze the level of job satisfaction in rural properties located in the municipality of Rio Brilhante/MS. For data collection, a structured questionnaire was used, developed according to the EST-Reduced multidimensional scale. The results unanimously found a pattern of satisfaction level for both

\footnotetext{
${ }^{1}$ Mestre em Desenvolvimento Regional e de Sistemas Produtivos.

${ }^{2}$ Mestre em agronegócio.

${ }^{3}$ Mestrando no Programa de Pós-graduação em Contabilidade da Universidade Federal de Mato Grosso do Sul (UFMS).

${ }^{4}$ Doutor em Geografia.
} 
properties. However, it was found that property A had the lowest average score in dimension 1 - Satisfaction with colleagues (4.62), as well as property B, in dimension 3 - Satisfaction with the boss (4.83), being relevant managers to create mitigating measures for their correction, given that such results are factors that may affect the performance of properties.

Keywords: Job satisfaction. Performance. EST scale.

\section{Introdução}

O setor agrícola é apontado como uma importante atividade para o agronegócio brasileiro. Atualmente o país é considerado um importante produtor de alimentos em âmbito mundial (Saath \& Fachinello, 2018). Esse desempenho é reflexo de diversos fatores, como: o modelo de produção capitalista, produção de commodities agropecuárias e o processo migratório no sentido rural-urbano (Mattei, 2015).

A partir dessa nova estrutura de produção, gerou-se uma nova dinâmica nas relações econômicas e sociais no meio rural brasileiro; nessa perspectiva, como aponta Mattei (2015, p. 35), “a decisão sobre o que produzir e como produzir deixou de ser uma tarefa específica do agricultor e passou a ser condicionada por uma série de variáveis determinadas pelo conjunto de agentes econômicos envolvidos no processo produtivo".

Mediante esse cenário, observa-se que as propriedades rurais, em sua maioria, possuem maior preocupação voltada aos fatores técnicos, principalmente, à produção em si, dando pouca ênfase ao capital humano, sendo assim, raramente utilizam-se de práticas de recursos humanos para gerir sua mão de obra. Como reflexo disso, verifica-se o aumento de rotatividade e absenteísmo, presença de doenças laborais e diminuição do nível de satisfação por parte dos colaboradores (Siqueira, 2008).

Hansen e Straete (2020) referem-se à satisfação no trabalho como sendo as atitudes positivas ou disposições emocionais que os trabalhadores obtêm a partir da execução de sua atividade laboral, ou por meio dos aspectos de seus trabalhos. De acordo com Hoppock (1935), satisfação no trabalho é a combinação de quaisquer circunstâncias (psicológicas, fisiológicas e/ou ambientais) que permitam ao trabalhador dizer verdadeiramente: "Estou satisfeito com meu trabalho".

Rocha e Wagner (2017) salientam que colaboradores satisfeitos demonstram um maior contentamento ao referir-se à empresa em que trabalham, auxiliam seu colega de serviço e estão dispostos a ir além das responsabilidades que lhes são atribuídas. Por outro lado, quando há insatisfação, percebe-se o aumento do absenteísmo e rotatividade, além de uma diminuição na produtividade e na qualidade produzida pelos empregados (Wagner \& Hollenbeck, 1999; Sbissa, 2017).

Revista Gestão e Secretariado (GeSec), São Paulo, SP, v. 12, n. 3, set./dez., 2021, p. 89-110. 
Para Sirotenco (2007), uma das causas do declínio no compromisso organizacional está diretamente relacionada à insatisfação, sendo assim "não é possível ter uma organização excelente, dinâmica, que busque resultados positivos, se o componente humano se encontra perdido ou confuso" (O’Donnel, 1997, p. 19).

Dado o tema satisfação no trabalho ser apontado como um fenômeno complexo e de difícil mensuração, haja vista o significado atribuído ao trabalho ser individual, subjetivo e multidimensional (Fiorelli et al. 2010), faz-se necessário à utilização de mecanismos que permitam sua avaliação. Dentre estas ferramentas de avaliação, pode-se citar a Escala de Satisfação no Trabalho - EST, desenvolvida por Siqueira (2008). Construída e validada no Brasil, a EST é uma medida multidimensional que tem como objetivo avaliar o grau de contentamento do trabalhador frente às cinco dimensões, a saber: satisfação com os colegas de trabalho, satisfação com o salário, satisfação com a chefia, satisfação com a natureza do trabalho e satisfação com as promoções (Siqueira, 2008).

A partir do exposto, este estudo objetivou analisar o nível de satisfação no trabalho em propriedades rurais (produtora de milho e soja) localizadas no município de Rio Brilhante/MS, a partir do uso da ferramenta de avaliação - EST reduzida. É pertinente aludir para a importância da realização deste tipo de estudo, uma vez que o setor rural além de ser tipificado como um dos mais perigosos em relação à saúde e segurança do trabalhador (World Health Organization, 1995), necessita buscar meios de reter sua mão de obra, posto que, o setor atualmente necessita lidar com a falta de mão de obra qualificada, sendo este um dos gargalos a serem superados pelo agronegócio brasileiro.

\section{Fundamentação teórica}

Nesta seção é apresentada a especificidade do trabalho no meio rural, o conceito sobre satisfação no trabalho e a importância de se avaliar o nível de satisfação dos colaboradores, conforme descrito em sequência.

\subsection{Especificidades do trabalho no meio rural}

O ramo de atividade agrícola é considerado perigoso em relação à saúde e segurança do trabalhador, haja vista este setor apresentar um expressivo percentual de acidentes, lesões e doenças variadas (Alves \& Guimarães, 2012).

Para Leite et al. (2007), o trabalho rural se difere das outras atividades, dadas suas características peculiares como: sazonalidade e caráter cíclico, esforço físico intenso, exposição 
constante às mudanças de clima, dentre outros. Para Lucca et al. (2011), o trabalhador rural durante sua atividade laboral está exposto a uma série de riscos de acidentes ocupacionais, sendo esses riscos classificados em físicos, químicos, biológicos, mecânicos e organizacionais, como: ergonômicos, ambientais e sociais, conforme descrito na Tabela 1 (Martins \& Ferreira, 2015).

Tabela 1. Riscos do trabalho rural.

\begin{tabular}{|c|c|}
\hline Riscos & Descrição dos riscos \\
\hline Físicos & $\begin{array}{l}\text { Vibrações provenientes dos maquinários, radiações não ionizantes que podem levar ao } \\
\text { desenvolvimento de câncer de pele, variações de temperatura devido às condições climáticas, } \\
\text { frio, calor; }\end{array}$ \\
\hline Químicos & $\begin{array}{l}\text { Exposição à agrotóxicos, à adubos químicos, fertilizantes, solventes, combustíveis, à gases } \\
\text { emanados da combustão de motores; }\end{array}$ \\
\hline Biológicos & $\begin{array}{l}\text { Exposição aos agentes biológicos (fungos, bactérias, protozoários etc.) existentes na terra, em } \\
\text { adubos orgânicos e na água, promovendo um aumento de probabilidade na ocorrência de } \\
\text { enfermidades infecciosas e verminoses; }\end{array}$ \\
\hline $\begin{array}{l}\text { Agentes } \\
\text { ergonômicos }\end{array}$ & $\begin{array}{l}\text { Causados por posturas inadequadas e carregamento de peso, posturas forçadas, } \\
\text { repetitividade, flexão/rotação de tronco; }\end{array}$ \\
\hline Psicológicos & Devido à pressão no trabalho e pressão por produtividade; \\
\hline Acidentes & $\begin{array}{l}\text { Cortes e amputações decorrentes do uso de ferramentas e de máquinas em condições } \\
\text { precárias de segurança; quedas, ataques de animais peçonhentos e domésticos; e acidentes de } \\
\text { trajetos; }\end{array}$ \\
\hline Ambientais & Contaminação hídrica, chuva ácida, pulverização aérea; \\
\hline
\end{tabular}
Fonte: Adaptado de Martins; Ferreira, (2015, p. 127).

Além dos fatores de riscos oriundos das atividades rurais implicarem diretamente sobre a saúde geral do trabalhador, este influencia diretamente na qualidade de vida, assim como na motivação e satisfação do trabalhador. Diante disso e na intenção de promover um ambiente de trabalho mais harmônico, agradável, saudável e seguro, faz-se necessário a adoção de políticas de gestão de pessoas. Para Pereira (2000), a gestão de pessoal permite assegurar a qualidade no campo, garantindo um bom ambiente de trabalho, maior satisfação dos trabalhadores e, consequentemente, melhoria na produtividade individual.

\subsection{Satisfação no ambiente de trabalho}

O termo satisfação no trabalho pode ser considerado como um fenômeno complexo e de difícil definição, visto que é vinculado ao estado subjetivo das pessoas, de forma ampla seu 
conceito varia de pessoa para pessoa, assim como de circunstância para circunstância (Martinez \& Paraguay, 2003).

Conforme entendimento de Robbins (2005, p.74), satisfação no trabalho pode ser conceituado "como a atitude geral de uma pessoa em relação ao trabalho que realiza". De acordo com Robbins (2005), alguns fatores podem influenciar para a satisfação no trabalho, dentre esses estão: a) os aspectos relacionados às tarefas mentalmente desafiadoras, b) às recompensas justas e adequadas, c) às condições de trabalho estimulantes e d) às relações entre os colaboradores e chefes; assim como tratar os funcionários com respeito, fornecer reconhecimento, capacitar os funcionários, oferecer benefícios e compensações, além de uma gestão positiva (Martins, 2017).

Quando os colaboradores estão satisfeitos, demonstram disposição para falar bem da organização, executar suas tarefas de forma colaborativa, atuam de forma eficaz e eficiente, bem como produzem acima das expectativas em relação ao seu trabalho, haja vista terem como propósito o de retribuir suas experiências positivas (Robbins, 2005).

"Por outro lado, se você não vê justiça em seu chefe, nos procedimentos da empresa ou na sua política de remuneração, sua satisfação com o trabalho decai consideravelmente" (Robbins, 2005, p. 78). Essa insatisfação "pode ser expressa de diversas formas: pedido de demissão, reclamações, insubordinação, furtos e fuga da responsabilidade" (Andrade et al., 2007, p. 77). Para Sbissa et al. (2017), o alto nível de insatisfação no ambiente de trabalho tende a gerar problemas para a organização, pois influencia diretamente no aumento da rotatividade e na diminuição da produtividade e da qualidade produzida.

"Estar ou não satisfeito em relação ao trabalho incorre em consequências diversas, sejam elas no plano pessoal ou profissional, afetando diretamente o comportamento, a saúde e o bemestar do trabalhador" (Marqueze \& Moreno, 2005, p.75). De acordo com Bergamini (2008), o fracasso da maioria das organizações não está relacionado diretamente à ausência de conhecimento técnico, mas sim na maneira como elas se relacionam com seus colaboradores.

Nesse contexto, compreender a satisfação no trabalho torna-se importante, uma vez que essa variável tem sido sinalizada como um dos fatores essenciais no comportamento organizacional (Rocha \& Wagner, 2017). Para Sbissa et al. (2017, p. 149), “as empresas podem oferecer várias ferramentas necessárias para o trabalhador executar suas funções. Contudo, se eles não estiverem satisfeitos e motivados para a realização de suas atividades, o rendimento não alcançará a produtividade desejada". 


\subsection{Por que avaliar o nível de satisfação dos colaboradores?}

A psicologia da motivação no trabalho diz respeito às necessidades de os trabalhadores serem atendidas para que estes experimentem o bem-estar mental e a satisfação em relação ao seu trabalho (Kolstrup \& Hultgren, 2012). Para Manto (2017), o fator satisfação no trabalho pode influenciar positivamente ou negativamente na saúde organizacional; dessa forma, a partir de "uma análise minuciosa dos colaboradores, uma empresa pode compreender quais são os aspectos mais relevantes para a saúde organizacional e a partir disso traçar possíveis estratégias" (Manto, 2017, p. 15).

De acordo com Martins (2017), o nível de satisfação de colaboradores deve ser mensurado constantemente, na intenção de que este sirva como um parâmetro para que a organização consiga manter seus colaboradores felizes, mesmo que para isso seja necessária à adoção de algumas estratégias específicas, por exemplo, a de endomarketing.

Neste contexto, Mendes e Ferreira (2008, p. 111) salientam que "diagnosticar como os trabalhadores avaliam o seu ambiente de trabalho se constitui em um importante desafio para as abordagens das ciências do trabalho". De acordo com os autores, captar, tratar e analisar as opiniões e sentimentos que os colaboradores apresentam acerca do ambiente de trabalho são aspectos importantes, dessa forma, sendo considerado como um diferencial que pode refletir em mudanças no bem-estar do trabalho, assim como na eficiência e eficácia dos processos produtivos.

Para Siqueira (2008, p. 265) "existem autores que defendem a satisfação no trabalho como indicador de desempenho laboral importante para o interesse empresarial, tais como aumento do desempenho e da produtividade, permanência na empresa e redução de faltas ao trabalho".

Sendo assim, conhecer a satisfação do funcionário torna-se um fator necessário para qualquer organização, pois, a partir destas informações, os gestores terão mais segurança para a tomada de decisão em relação aos seus colaboradores (Sbissa, 2017, p. 148), dado que esse fator é reflexo de como o indivíduo se sente em relação ao trabalho, ou seja, o quanto o colaborador está satisfeito com o seu trabalho (Spector, 2003).

Portanto, como qualquer organização, as propriedades rurais necessitam avaliar o nível de satisfação no trabalho de seus colaboradores, principalmente nos cenários em que o setor se depara, onde um dos principais problemas do setor rural é a falta de mão de obra qualificada. Logo, é a partir da avaliação do nível de satisfação no trabalho que o produtor rural terá a real percepção de como seu colaborador se sente em função do trabalho que executa e, a partir disso, 
conseguirá criar estratégia para melhorar a satisfação no trabalho e dessa forma, criar políticas com vista a reter sua mão de obra. Sink e Tutle (1993, p.7) corroboram ao afirmar que "é difícil, se não impossível, gerenciar de modo eficaz algo que não é medido corretamente”. Segundo os autores, não se pode gerenciar aquilo que não se pode medir.

\section{Material e métodos}

Essa pesquisa desenvolveu-se em uma abordagem qualitativa. Quanto aos fins, caracteriza-se como descritiva, sendo realizada a partir de um estudo multicaso. Para Yin (2015), o estudo de caso é de extrema importância para a compreensão de fenômenos individuais, organizacionais, sociais e políticos, e pode envolver tanto casos singulares quanto múltiplos, e inúmeros níveis de análise.

O estudo foi desenvolvido no município de Rio Brilhante/MS, nas coordenadas geográficas: latitude de $21^{\circ} 48^{\prime} 07^{\prime} \mathrm{S}$, longitude $54^{\circ} 32^{\prime} 45^{\prime \prime} \mathrm{W}$ e altitude de 312 metros em relação ao nível médio do mar. O município possui uma área de $3.987,397$ km², e população de aproximadamente 38.186 habitantes (IBGE, 2020), conforme visualizado na Figura 1

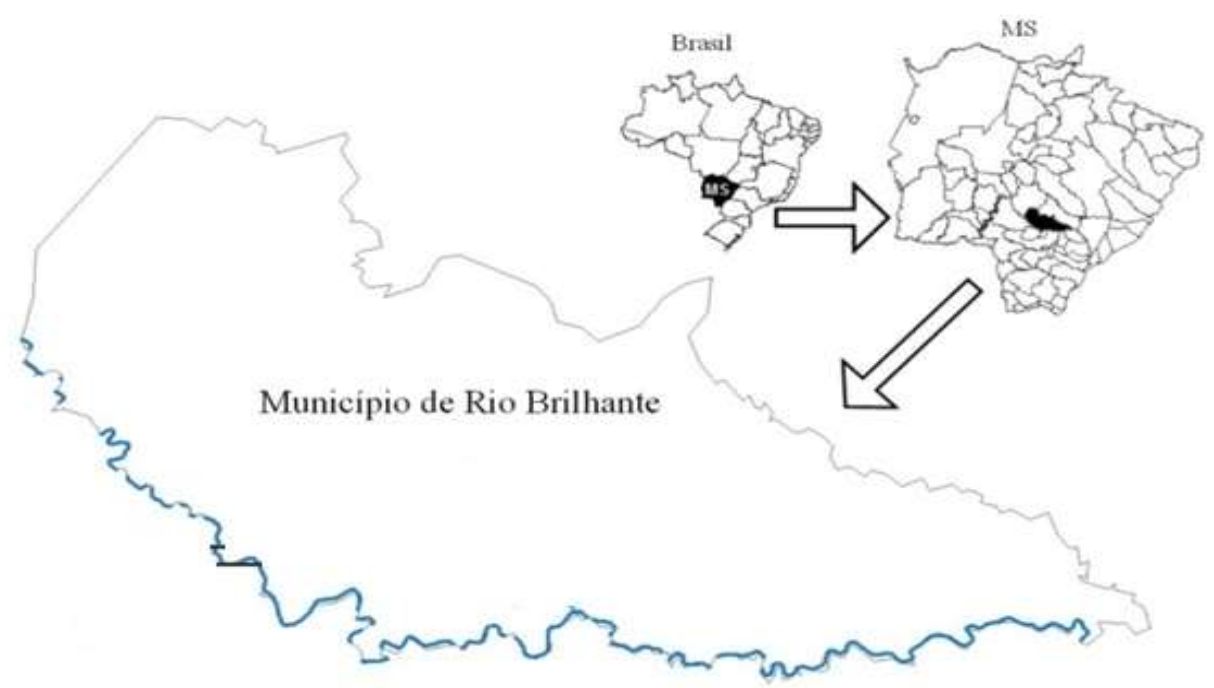

Figura 1. Localização da cidade de Rio Brilhante, Mato Grosso do Sul, Brasil. Fonte: Adaptado de Maceda et al. (2015).

As fontes de dados utilizados neste estudo constituíram-se basicamente de dados primários. Os dados foram coletados através de entrevistas estruturadas com aplicação de questionário contendo perguntas fechadas, sendo realizadas em duas propriedades rurais 
distintas, uma produtora de milho e outra produtora de soja, sendo entrevistado um total de oito colaboradores. A coleta ocorreu entre o meses de setembro a novembro de 2018. A escolha das propriedades deu-se em função de determinadas particularidades, ou seja, ambas possuem certas características similares como: tamanho da propriedade, número de funcionários, assim como a tecnologia utilizada (máquinas e equipamentos), principalmente as utilizadas para plantio e colheita.

O questionário foi composto por 22 perguntas, sendo 07 delas utilizadas para caracterizar o perfil dos funcionários e 15 para avaliar o grau de satisfação dos funcionários, conforme modelo da escala reduzida de satisfação no trabalho - EST Reduzida, desenvolvida por Siqueira (2008). As dimensões e itens que compõem a EST reduzida são apontados na Figura 02.

\section{Dimensão}

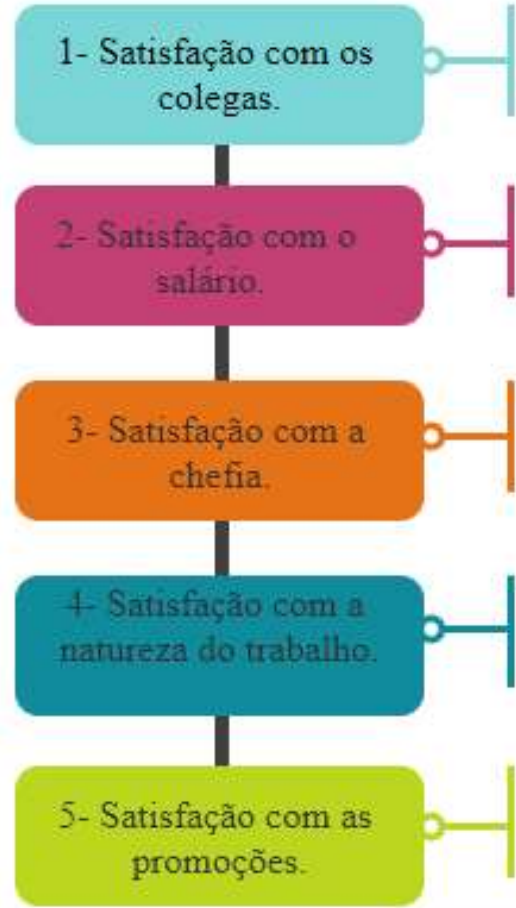

01- Espirito de colaboração de meus colegas.

04- Tipo de amizade que meus colegas demonstram por mim.

14- Confiança que eu posso ter em meus colegas de trabalho.

03- Meu salário comparado ao quanto eu trabalho.

06- Meu salário comparado à minha capacidade profissional.

11- Meu salário comparado aos meus esforços no trabalho.

10- Entendimento entre eu e meu chefe

12- Maneira como meu chefe me trata.

15- Capacidade profissional do meu chefe.

05- Grau de interesse que minhas tarefas me despertam.

08- Capacidade de meu trabalho absorver-me.

13- Variedade de tarefa que realizo.

02- Número de vezes que já fui promovido nesta empresa.

07-Maneira como esta empresa realiza promoções de seu pessoal. 09 -

Oportunidades de ser promovido nesta empresa.

Figura 2. Descrição das cinco dimensões e das 15 variáveis da escala de satisfação no trabalho - EST reduzida. Fonte: Elaborado pelos autores a partir de Siqueira, (2008).

As questões foram desenvolvidas com escala de respostas do tipo "Likert" (escala ordinal de sete categorias), em que os pesquisados responderam a cada quesito por intermédio de vários graus de concordância numerados de 1 a 7, sendo: 1 (Totalmente Insatisfeito), 2 (Muito Insatisfeito), 3 (Insatisfeito), 4 (Indiferente), 5 (Satisfeito), 6 (Muito Satisfeito) e 7 (Totalmente Satisfeito). 
Para se chegar à nota final, efetuou-se o cálculo da média das notas atribuídas a cada dimensão, resultado no escore médio, sendo que os resultados dos escores médios devem ficar entre 1 e 7 (Siqueira, 2008). A partir das respostas, Siqueira (2008, p. 271) explica que "a interpretação dos resultados deverá considerar que quanto maior for o valor do escore médio, maior será o grau de contentamento ou satisfação do empregado com aquela dimensão de seu trabalho", ou seja, os valores entre 5 e 7 tendem a indicar satisfação, valores entre 4 e 4,9 expressam um estado de neutralidade, ou seja, nem satisfeito, nem insatisfeito e valores entre 1 e 3,9 apontam insatisfação.

Os dados foram mensurados através de planilhas inseridas na plataforma Microsoft Excel, sendo determinadas as médias de cada uma das 15 variáveis, assim como de cada uma das cinco dimensões. Os resultados foram apresentados em forma de tabelas, juntamente com suas respectivas discussões.

\section{Análise e discussão dos resultados}

Neste item são descritos os resultados alcançados com a aplicação da pesquisa realizada nas duas propriedades, sendo a propriedade produtora de milho denominada de propriedade A e a propriedade produtora de soja denominada de propriedade $\mathrm{B}$. $\mathrm{Na}$ análise dos resultados, apresenta-se inicialmente o perfil da amostra e posteriormente a análise do nível de satisfação através da Escala de Satisfação no Trabalho - EST reduzida, de Siqueira (2008).

\subsection{Perfil dos entrevistados}

De acordo com as informações descritas na Tabela 2, observa-se uma similaridade entre a faixa etária dos entrevistados de ambas as propriedades (A e B). Por outro lado, em relação ao gênero, nota-se uma predominância absoluta (100\%) de trabalhadores do sexo masculino na propriedade B, enquanto na propriedade A estimativa desse gênero está em torno de $75 \%$.

Em relação ao estado civil, constata-se que a incidência entre casados e solteiros são similares (50\%) para os respondentes das duas propriedades (A e B). No que se refere ao grau de escolaridade, nota-se que a maior parte dos respondentes $(50 \%)$ de ambas as propriedades (A e B) apresentam o ensino médio completo, em consonância aos resultados obtidos por Silva (2016), que observou que em torno de $75 \%$ dos entrevistados que compõem a amostra de sua pesquisa possuem o ensino médio completo. 
Tabela 2. Perfil dos trabalhadores rurais entrevistados em Rio Brilhante - MS.

\begin{tabular}{|c|c|c|c|c|}
\hline \multirow[t]{2}{*}{ Descrição } & \multicolumn{2}{|c|}{ Propriedade A } & \multicolumn{2}{|c|}{ Propriedade B } \\
\hline & Características & $\%$ & Características & $\%$ \\
\hline \multirow{3}{*}{ Faixa etária } & Até 30 anos & $50 \%$ & Até 30 anos & $25 \%$ \\
\hline & 31 a 40 anos & $25 \%$ & 31 a 40 anos & $25 \%$ \\
\hline & Acima de 50 anos & $25 \%$ & Acima de 50 anos & $50 \%$ \\
\hline \multirow{2}{*}{ Gênero } & Masculino & $75 \%$ & Masculino & $100 \%$ \\
\hline & Feminino & $25 \%$ & Feminino & $0 \%$ \\
\hline \multirow{2}{*}{ Estado civil } & Casado & $50 \%$ & Casado & $50 \%$ \\
\hline & Solteiro & $50 \%$ & Solteiro & $50 \%$ \\
\hline \multirow{4}{*}{ Escolaridade } & $\begin{array}{l}\text { Fundamental } \\
\text { Incompleto }\end{array}$ & $25 \%$ & $\begin{array}{l}\text { Fundamental } \\
\text { Incompleto }\end{array}$ & $0 \%$ \\
\hline & Fundamental Completo & $50 \%$ & Fundamental Completo & $50 \%$ \\
\hline & Médio incompleto & $25 \%$ & Médio incompleto & $25 \%$ \\
\hline & Superior completo & $0 \%$ & Superior completo & $25 \%$ \\
\hline \multirow{4}{*}{$\begin{array}{l}\text { Tempo que trabalha na } \\
\text { propriedade: }\end{array}$} & Até 1 ano & $25 \%$ & Até 1 ano & $25 \%$ \\
\hline & Até 2 anos & $25 \%$ & Até 2 anos & $25 \%$ \\
\hline & Até 4 anos & $50 \%$ & Até 4 anos & $0 \%$ \\
\hline & Acima de 5 anos & $0 \%$ & Acima de 5 anos & $50 \%$ \\
\hline $\begin{array}{l}\text { Indicaria a propriedade } \\
\text { como um local ótimo para } \\
\text { trabalhar }\end{array}$ & Sim & $100 \%$ & Sim & $100 \%$ \\
\hline $\begin{array}{l}\text { A propriedade atende seus } \\
\text { anseios financeiro, pessoal } \\
\text { e profissional. }\end{array}$ & Sim & $100 \%$ & Sim & $100 \%$ \\
\hline
\end{tabular}

Fonte: Dados da pesquisa.

Do total de entrevistados das duas propriedades (Tabela 2), 100\% salientaram que indicariam a propriedade como um local ótimo para trabalhar; no mesmo patamar percentual $(100 \%)$, enfatizaram que a propriedade onde trabalham atende seus anseios, sejam estes de cunho financeiro, pessoal ou profissional.

\subsection{Avaliação da satisfação no trabalho: aplicação da pesquisa EST - Reduzida}

A seguir são apresentados os resultados obtidos em cada uma das cinco dimensões analisadas através da aplicação do método de avaliação EST - reduzida.

\subsubsection{Dimensão 1 - satisfação com os colegas}

Esta dimensão avalia a satisfação do colaborador sobre seu: espírito de colaboração com os colegas de trabalho, a amizade, a confiança e o relacionamento mantido com os colegas de trabalho. Os resultados obtidos estão descritos na Tabela 3. 
Tabela 3. Dimensão - satisfação com os colegas.

\begin{tabular}{l|c|c}
\hline \multicolumn{1}{c|}{ VARIÁVEIS } & \multicolumn{2}{c}{ MÉDIA } \\
\cline { 2 - 3 } & Propriedade A & Propriedade B \\
\hline Espírito de colaboração dos meus colegas de trabalho. & 5,50 & 6,25 \\
Tipo de amizade que meus colegas demonstram por mim. & 4,25 & 6,00 \\
Confiança que eu posso ter em meus colegas de trabalho. & 5,00 & 6,25 \\
\hline Escore Médio & 4,92 & 5,5 \\
\hline
\end{tabular}

Fonte: Dados da pesquisa.

As ponderações acusaram resultados diferentes entre as duas propriedades, enquanto a propriedade A obteve um escore médio de 4,92, o que sinaliza uma neutralidade dos funcionários em responderem as questões dessa dimensão, a propriedade B apontou um escore médio de 5,50, o que representa um grau de satisfação dos colaboradores.

Apesar dessa neutralidade (propriedade A), observa-se que os respondentes das duas propriedades demonstraram satisfação no que se refere à colaboração entre os funcionários e no nível de confiança entre eles. Este resultado ocorreu em função de os colaboradores enfatizarem que os colegas de trabalhos são empenhados, cada qual auxilia na execução das atividades contribuindo satisfatoriamente para que todos concluam seus afazeres da melhor forma possível, principalmente em época de colheita, onde se faz necessário contar com o trabalho em equipe, haja vista ser um período em que os funcionários chegam a ficar na propriedade em torno de 13 horas por dia, apesar da consolidação das leis de trabalho (CLT) determinarem que a jornada de trabalho máxima a ser cumprida pelo colaborador seja de oito horas diárias (Tribunal Superior do Trabalho, 2021).

Essa sobrecarga de trabalho, conforme entendimento de Rocha et al. (2015), tende a influenciar na saúde do trabalhador, repercutindo em adoecimentos e acidentes de trabalho. Sendo assim, de acordo Másculo e Vidal (2011), é importante que empregadores cumpram as legislações trabalhistas e as normas de saúde, higiene e segurança, com o intuito de promover um ambiente laboral mais saudável (Másculo \& Vidal, 2011).

Dado ambas as propriedades terem pontuado valores (entre 4 e 4,9 ) que expressam um estado de neutralidade na variável "tipo de amizade que meus colegas demonstram por mim", observa-se a necessidade dessas organizações promoverem atividades de interação, de modo a permitir que os trabalhadores possam se relacionar entre si. 


\subsubsection{Dimensão 2 - Satisfação com o salário}

Esta dimensão buscou avaliar a satisfação do funcionário com seu salário quando comparado com o quanto ele trabalha, com sua capacidade profissional, com o custo de vida (foi analisado na visão do respondente se o que eles recebem cobrem seus gastos mensais), assim como com os seus esforços na realização do trabalho. Os resultados obtidos nessa dimensão estão detalhados na tabela 4.

Tabela 4. Dimensão 2- Satisfação com o salário.

\begin{tabular}{l|c|c}
\hline \multicolumn{1}{c|}{ VARIÁVEIS } & \multicolumn{2}{c}{ MÉDIA } \\
\cline { 2 - 3 } & Propriedade A & Propriedade B \\
\hline Salário comparado com o quanto eu trabalho. & 5,00 & 6,25 \\
Salário comparado à minha capacidade profissional. & 5,00 & 6,50 \\
Salário comparado aos meus esforços no trabalho & 5,25 & 6,25 \\
\hline Escore Médio & 5,08 & 6,33 \\
\hline
\end{tabular}

Fonte: Dados da pesquisa.

A dimensão satisfação com o salário mostrou-se bastante aprazível, haja vista a média obtida nessa dimensão ser de 5,08 para a propriedade A e de 6,33 para a Propriedade B, apontando que os funcionários estão satisfeitos com o salário que recebem mensalmente. Apesar disso, os entrevistados não pontuaram nota máxima a este quesito, dada a ausência de programa de benefícios. Os respondentes mencionaram que o salário que recebem está de acordo com a atividade que desenvolvem e são pagos em dia, entretanto, o recebimento de certos benefícios extras (alimentação e ajuda de custo) os manteriam mais motivados para a execução de suas tarefas. Na propriedade A, os benefícios pagos se limitam apenas em auxíliotransporte, enquanto na propriedade B é disponibilizado ao colaborador auxílio-transporte e ajuda de custo. Para ambas as propriedades, de acordo com os respondentes, as horas extras trabalhadas são pagas.

$\mathrm{Na}$ visão de Stefano et al. (2014, p. 65), "um plano de benefícios possibilita aos colaboradores maiores níveis de satisfação, bem-estar e contribui para a redução do absenteísmo e rotatividade dos funcionários das organizações". Diante disso, fica evidente o quão importante é dispor um salário adequado aos funcionários, posto que, no entendimento de Favarim (2011, p. 213), "um dos fatores que mais desmotiva um profissional é quando esse 
considera-se injustiçado em sua remuneração, pois, isso o afeta tanto material como psicologicamente".

Sendo assim, torna-se fundamental para estas propriedades analisadas (A e B), especialmente considerando-se o nível de insatisfação com a ausência de benefícios, a promoção de estratégias voltadas para a implantação de benefícios extras, tendo em vista que os benefícios, em geral, trazem vantagens tanto para o colaborador quanto para a organização (Gaulke \& Nicoleti, 2007) e o não cumprimento dos direitos trabalhistas favorecem a desmotivação do trabalhador, visto que "a satisfação no trabalho depende do grau em que coincide o que um indivíduo procura no seu trabalho com o que realmente retira (Tamayo, 2000, p. 38).

\subsubsection{Dimensão 3 - Satisfação com a chefia}

Essa dimensão mensura o nível de satisfação com a chefia, a partir das variáveis: entendimento entre mim e meu chefe, maneira como meu chefe me trata e capacidade profissional do meu chefe. A Tabela 5 mostra os resultados obtidos na avaliação desta dimensão.

Tabela 5. Dimensão 3 - Satisfação com a chefia.

\begin{tabular}{l|c|c}
\hline \multirow{2}{*}{ VARIÁVEIS } & \multicolumn{2}{c}{ MÉDIA } \\
\cline { 2 - 3 } & Propriedade A & Propriedade B \\
\hline Entendimento entre eu e meu chefe. & 5,00 & 4,00 \\
Maneira como meu chefe me trata. & 5,00 & 6,50 \\
Capacidade profissional do meu chefe. & 5,00 & 4,00 \\
\hline Escore Médio & 5,00 & 4,83 \\
\hline
\end{tabular}

Fonte: Dados da pesquisa.

Nesta dimensão (satisfação com a chefia), os colaboradores da propriedade A mantiveram-se satisfeitos, logo é possível constatar que há um bom relacionamento entre os trabalhadores e sua chefia. Por outro lado, a propriedade B apresentou um resultado de 4,83, em que os funcionários se abstiveram de demonstrar sua real insatisfação, optando em manter neutralidade a esta dimensão.

De acordo com os entrevistados da propriedade B, embora seu chefe seja educado e prestativo, muita das vezes não leva em consideração a opinião dos seus colaboradores para a 
tomada de decisão, dessa forma sentem-se pouco estimulados e envolvidos nas atividades da propriedade, os que de certa forma, torna a interação entre ambos pouco espontâneos. Além disso, salientaram que em alguns casos seu chefe carece de conhecimento técnico para a tomada de decisão. Moraes et al. (2012) destacam que, quando não há espaço para que o colaborador possa ter autonomia em suas tarefas, a organização tende a ter prejuízo relacionado ao aperfeiçoamento do trabalho, pois ao ter suas ideias suprimidas, o trabalhador não consegue colocar em prática suas habilidades, o que, em geral, promovem insatisfação.

Os resultados enfatizam para a importância da figura de uma boa chefia para o alcance dos objetivos da empresa, assim como para a manutenção de um ambiente propício à satisfação dos funcionários, posto que este cenário de ausência de um bom relacionamento entre chefe e colaborador tende a influenciar no retorno financeiro da empresa.

Por exemplo, a realização da semeadura e/ou colheita (neste caso de soja e milho) deve ser feita em uma faixa ideal de velocidade de deslocamento, para que se obtenha um índice de produtividade; sendo assim, o não comprometimento e/ou desatenção do colaborador tende a repercutir em baixa produtividade, o que reflete nos resultados financeiros da atividade. É importante que a organização promova o relacionamento interpessoal entre o líder e membros da equipe, com intuito de estimular um clima de confiança, respeito e afeto (Carvalho, 2009).

"Muitas vezes, funcionários sentem-se mais à vontade com um supervisor que os considere, ou seja, um chefe que demonstre interesse por seus sentimentos e que forneça também oportunidades para que participem na tomada de decisões" (Davis \& Newstrom, 2004, p. 125). Em consonância, Carvalho (2009) salienta que em um ambiente de relacionamento harmonioso entre os membros da organização, as probabilidades de cooperação aumentam e a sinergia tende a ser alcançada, de modo a impactar satisfatoriamente nos resultados produtivos.

\subsubsection{Dimensão 4 - Satisfação com a natureza do trabalho}

$\mathrm{Na}$ dimensão satisfação com a natureza do trabalho, foram analisadas as seguintes variáveis: grau de interesse que minhas tarefas me despertam, capacidade de meu trabalho absorver-me e variedade de tarefa que realizo. Os resultados auferidos estão ilustrados na Tabela 6. 
Tabela 6. Dimensão 4 - Satisfação com a natureza do trabalho.

\begin{tabular}{l|c|c}
\hline \multirow{2}{*}{ VARIÁVEIS } & \multicolumn{2}{c}{ MÉDIA } \\
\cline { 2 - 3 } & Propriedade A & Propriedade B \\
\hline Grau de interesse que minhas tarefas me despertam. & 5,00 & 6,00 \\
Capacidade de meu trabalho absorver-me. & 5,25 & 6,25 \\
Variedade de tarefas que realizo. & 5,50 & 6,50 \\
\hline Escore Médio & 5,25 & 6,25 \\
\hline
\end{tabular}

Fonte: Dados da pesquisa.

Os dados evidenciam que os trabalhadores estão satisfeitos em relação a essa dimensão; a propriedade A obteve uma média de 5,25, enquanto na propriedade B foi de 6,25.

Esses resultados sugerem que os colaboradores gostam da atividade que realizam e do local onde trabalham, o que influencia positivamente no clima organizacional. De acordo com os colaboradores, ainda que a atividade que realizam seja na maioria das vezes cansativa, braçal e estressante, estes se apresentam contentes de uma forma geral, em trabalharem com a atividade rural, uma vez que essa atividade lhes permite utilizarem de sua capacidade e conhecimento para a realização de suas tarefas. Segundo os relatos de um dos trabalhadores entrevistados, "sinto-me importante pelo que faço".

Logo, essa situação reforça um nível de satisfação dos entrevistados, pois se observa "um estado emocional prazeroso ou positivo resultante da avaliação das experiências de trabalho de uma pessoa com o cumprimento de seu trabalho", sendo este uma definição de nível de satisfação do trabalho, conforme apontado por Steinhardt et al. (2003, p. 1).

\subsubsection{Dimensão 5 - Satisfação com as promoções}

Essa dimensão avalia o nível de satisfação com as promoções a partir das variáveis: número de vezes que já fui promovido na empresa, maneira como essa empresa realiza as promoções e satisfação com as oportunidades de promoção. Os resultados são apresentados na Tabela 7. 
Tabela 7. Dimensão 5 - Satisfação com as promoções.

\begin{tabular}{l|c|c}
\hline \multirow{2}{*}{ VARIÁVEIS } & \multicolumn{2}{c}{ MÉDIA } \\
\cline { 2 - 3 } & Propriedade A & Propriedade B) \\
\hline Número de vezes que já fui promovido nesta empresa. & 6,00 & 6,25 \\
Maneira como esta empresa realiza promoções de seu pessoal. & 6,25 & 6,25 \\
Oportunidades de ser promovido nesta empresa & 6,50 & 6,50 \\
\hline Escore Médio & 6,25 & 6,33 \\
\hline
\end{tabular}

Fonte: Dados da pesquisa.

A performance da dimensão satisfação com as promoções apontaram um nível de satisfação para ambas as propriedades, em que a propriedade A obteve um escore médio de 6,25 e a propriedade B de 6,33. De modo unânime, os colaboradores de ambas as propriedades salientaram que estão contentes com a forma como a promoção são realizadas, apesar das promoções não ocorrerem constantemente, em função das propriedades serem de pequeno porte e não disponibilizarem muitos cargos para serem preenchidos.

Os respondentes salientam que os colaboradores que têm a intenção de progredir rapidamente acabam se desligando da empresa e procurando outro local para trabalharem. Wood Júnior e Picarelli (2004, p. 76) mencionam que "se a organização perder alguns de seus profissionais, ela não estará perdendo apenas alguns recursos humanos e sim uma parte intangível de seu capital - o humano". Considerando o exposto, a perda de mão de obra dada à ausência de um ambiente propicio ao crescimento profissional dos colaboradores tende a contribuir para a insatisfação dos que permanecem na empresa e gerar um ambiente de incerteza aos que querem continuar a trabalhar na propriedade, mas que almejam progredir profissionalmente. Sendo assim, é necessária que a organização possua uma visão holística, a fim de entender a satisfação no trabalho em nível individual (Hansen \& Straeteb, 2020).

A partir dessa avaliação foi possível chegar a uma avaliação geral da satisfação para cada dimensão, tanto para a propriedade A, quanto para a propriedade B (Figura 3). 


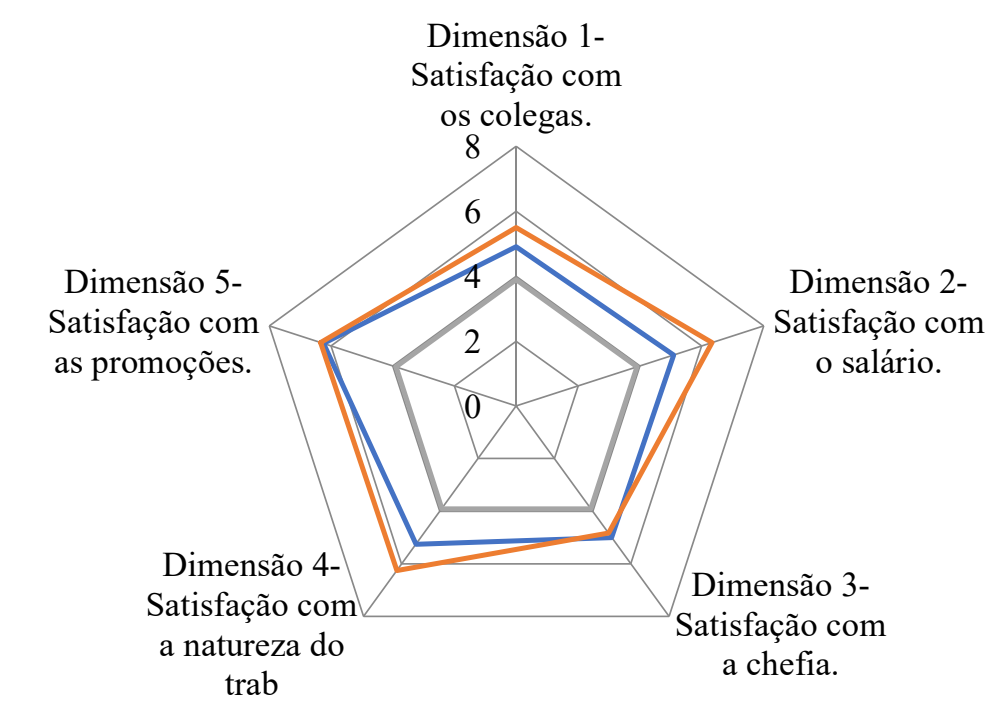

$\begin{array}{lcl} & \text { Prop. (A) } & \text { Prop. (B) } \\ \text { Dimensão 1. } & 4,92 & 5,50 \\ \text { Dimensão 2. } & 5,08 & 6,33 \\ \text { Dimensão 3. } & 5,00 & 4,83 \\ \text { Dimensão 4. } & 5,25 & 6,25 \\ \text { Dimensão 5. } & 6,25 & 6,33\end{array}$

—Desempenho- Propriedade (A) ——Desempenho- Propriedade (B) —— Linha Base- Grau de Insatisfação

Figura 3. Resultados da avaliação do nível de satisfação no trabalho (EST-reduzida) das propriedades A e B, por dimensão pesquisada.

Fonte: Dados da pesquisa.

A partir destes resultados (Figura 3), pode-se constatar que, embora as propriedades não tenham pontuado um valor máximo para o nível de satisfação (valor 7), os colaboradores não apresentaram insatisfação para nenhuma das cinco dimensões (valor entre 1 e 3,9). Mediante este fato, observa-se que, mesmo que a atividade no meio rural (nesse caso em propriedade produtora de milho e soja) seja vista como estressante e na maioria das vezes insalubre, de um modo unânime a avaliação do nível de satisfação em ambas as propriedades evidenciaram resultados positivos. Entretanto, torna-se necessário que os gestores de ambas as propriedades criem mecanismos para mitigar a média obtida na dimensão 1 recebida pela propriedade A e na média obtida na dimensão 3 pela propriedade $\mathrm{B}$, no intuito de promover melhoria.

Diante dos resultados, verifica-se a importância de a empresa manter um ambiente propício à satisfação de seus colaboradores, uma vez que esse fator influencia diretamente no sucesso das organizações, em geral, sejam estas rurais ou urbanas. Além disso, é um dever social das organizações zelar pelo bem-estar de seus funcionários, uma vez que, de acordo com Quilici e Xavier (2006), atualmente os trabalhadores passam a maior parte de sua vida no ambiente laboral (mais de 8 horas por dia) pelo menos 35 anos de suas vidas e, dessa forma, "não se trata mais de levar os problemas de casa para o trabalho, e sim de levarmos para casa 
os problemas, as tensões, as angústias e os receios acumulados no ambiente de trabalho" (Quilici \& Xavier, 2006, p. 2).

\section{Considerações finais}

Foi possível perceber que propriedades rurais, assim como qualquer empresa, possuem a necessidade de proporcionar meios para manter seus funcionários satisfeitos, uma vez que tais políticas se tornam importantes para a retenção de mão de obra, posto que, atualmente, a ausência de mão de obra qualificada é um dos maiores empecilhos do agronegócio.

Por meio desse estudo, constatou-se de forma unânime que todos os entrevistados se encontram satisfeitos com o trabalho que executam. Entretanto, verificou-se que a média obtida na dimensão 1 (propriedade A) e 3 (propriedade B) está aquém do desejado. Diante do exposto, os produtores necessitam desenvolver medidas mitigadoras para a correção de tais empecilhos, haja vista a propensão destes elementos em tornarem-se fatores prejudiciais ao bem-estar dos funcionários, assim como para o sucesso das propriedades objeto deste estudo.

A limitação da pesquisa refere-se à resistência dos pesquisados em expressar sua opinião real, na qual se observou a neutralidade a determinadas questões, mesmo demonstrando um sentimento de insatisfação.

Os resultados obtidos permitirão que os donos das propriedades analisadas tenham ciência do impacto que sua atividade gera (positivo ou negativo) para o bem-estar de todos os envolvidos, consentindo a eles criarem estratégias exequíveis e direcionadas às reais necessidades de seus colaboradores. Sob esse aspecto, este estudo certamente contribuirá para a disseminação da importância de se analisar a satisfação no trabalho, mais precisamente no setor rural, dado que esse setor carece de trabalhos na área de gestão de pessoas.

Neste contexto, a avaliação do nível de satisfação no trabalho através do uso da EST Reduzida representa uma ferramenta útil, de fácil entendimento e aplicação, sendo, portanto, indicada ao uso do produtor rural.

\section{Referências}

Alves, R. A. \& Guimarães, M. C. (2012). De que sofrem os trabalhadores rurais? - Análise dos principais motivos de acidentes e adoecimentos nas atividades rurais. Informe Gepec, 16(2), 39-56, 2012. 
Andrade, C. R. de.; Pereira, L. Z. \& Ckagnazaroff, I. B. (2007). Elementos de satisfação e insatisfação no trabalho operacional: revisitando Herzberg. Revista gestão \& tecnologia, $8(1) 67-89$.

Bergamini, C. W. (2008). Motivação nas organizações. 5. ed. São Paulo: Atlas.

Carvalho, M. do C. N. de. (2009). Relacionamento Interpessoal: como preservar o sujeito coletivo. Rio de Janeiro: LTC.

Davis, K. \& Newstrom J. W. (2004). Comportamento humano no trabalho: uma abordagem psicológica. São Paulo: Pioneira Thomson Learning.

Favarim, F. N. (2011). Remuneração e salário uma abordagem jurídico/administrativa. Revista de ciências gerenciais, 15 (21), 209-224.

Fiorelli, C., Porcher, J. \& Dedieu, B. (2010) Improving farm working conditions: A proposal to characterise the individual relationship to work. A case study based on French multijobholder sheep farmers. 1117-1128 in I. Darnhofer and M. Grötzer eds, Proceedings of the 9th European IFSA Symposium (Vienna: Universität für Bodenkultur). July 2010.

Gaulke, C. N. \& Nicoleti, G. G. (2007). Benefícios: usado como fator motivacional pela empresa Karsten S/A no setor tecelagem. Revista Interdisciplinar Cientifica Aplicada, $1(2), 1-15$.

Hansen, B. G \& Straete, E. P. (2020). Dairy farmers' job satisfaction and the influence of automatic milking systems. Wageningen Journal of Life Sciences, 92, 3-13.

Hoppock R. (1935). Job satisfaction. New York: Harper and Brothers.

IBGE. Instituto Brasileiro de geografia e estatística (2020). População estimada de Rio Brilhante. Disponível em: <https://cidades.ibge.gov.br/brasil/ms/rio-brilhante/panorama $>$ Acesso em: 20 jun. 2021.

Kolstrup, C. L. \& Hultgren, J. (2011). Perceived physical and psychosocial exposure and health symptoms of dairy farm staff and possible associations with dairy cow health. Journal of Agricultural Safety and Health, 17, 111-125.

Leite, B. R. B., Cabral, F. P.\& Suett, W. B. (2007). Importância da ergonomia e segurança do trabalho na melhoria das condições de trabalho do trabalhador canavieiro. Anais do Encontro Nacional de Engenharia de Produção. Foz do Iguaçu, PR, Brasil, 27.

Lucca, S. R., Cortez, M. Z. \& Tosetto, T. (2011). A percepção dos trabalhadores sobre os riscos de distúrbios osteomusculares relacionados ao trabalho na produção de rosas. Revista Espaço Diálogo e Desconexão, 4(1). s.p. 
Maceda, E. B., Grisolia, A. B., Vaini, J. O. \& Candido, L. S. (2015). Uso de biomarcadores para monitoramento das águas do Córrego Arara no município de Rio Brilhante, MS, Brasil. Revista ambiente e água, 10(1), 117-129.

Manto, R. (2017). Avaliação do nível de satisfação no trabalho dos colaboradores de uma cooperativa de crédito Catarinense. Trabalho de Conclusão de Curso. Universidade da Fronteira do Sul, Chapecó, RS, Brasil.

Marqueze, E. C.\& Moreno, C. R. de C. M. (2005). Satisfação no trabalho - uma breve revisão. Revista Brasileira de Saúde Ocupacional, 30(112), 69-79.

Martinez, M. C. \& Paraguay, A. I. B. B. (2003). Satisfação e saúde no trabalho - aspectos conceituais e metodológicos. Cadernos de Psicologia Social do Trabalho,

Martins, T. (2017). Como medir a satisfação de colaboradores com a empresa. Disponível em: $<$ https://meuaio.com/blog/satisfacao-de-colaboradores/>. Acesso em: 21 jan. 2021.

Martins, A. J.\& Ferreira, N. S. (2015). A ergonomia no trabalho rural. Revista eletrônica Atualiza Saúde, 2(2), 125-134.

Másculo, F. S. \& Vidal, M. C. (2011). Ergonomia: Trabalho Adequado e Eficiente. Rio de Janeiro: Elsevier, 648 p.

Mattei, L. (2015). Emprego agrícola: cenários e tendências. Estudos avançados, 29 (85), 3552.

Mendes, M. C.\& Ferreira, A.M. (2008). Contexto de trabalho. In: Siqueira, M. M. (Org.) Medidas de comportamento Organizacional: Ferramenta de diagnóstico e gestão. Porto Alegre RS: Artmed, 111-123.

Moraes, R. D. de, Vasconcelos, A. C. L. \& Cunha, S. C. de P. da. (2012). Prazer no Trabalho: O Lugar da Autonomia. Revista Psicologia: Organizações e Trabalho,12 (12), 217-228.

O'donnel, K. (1997). Endoquality: as dimensões emocionais e espirituais do ser humano nas organizações. Salvador: casa da qualidade.

Pereira, M. A. (2000). Gestão de Pessoal em empresas rurais: o caso da bovinocultura de corte. Anais do Congresso brasileiro das raças zebuínas, Uberaba. 4.

Quilici, R. F. M. \& Xavier, A. A. de P. (2006). Qualidade de Vida no Trabalho (QVT) em uma empresa estocadora de soja na região dos Campos Gerais: um estudo comparativo sobre satisfação/motivação. Anais do encontro nacional de engenharia de produção. Fortaleza, 26.

Robbins, S. P. (2005). Comportamento organizacional. 11 ed. São Paulo: Pearson Education, 
Rocha, A. C. da \& Wagner, C. (2017). Avaliação da satisfação no trabalho: estudo em uma empresa distribuidora de autopeças. Revista de Micro e Pequenas Empresas e Empreendedorismo da Fatec, 3(1), 118-139.

Rocha, L. P., Cezar-Vaz, M. R., Almeida, M. C. V., Borges, A. M., Silva, M. S. \& SenaCastanheira, J. (2015). Cargas de trabalho e acidentes de trabalho em ambiente rural. Texto Contexto Enferm, Florianópolis, 24(2), 325-35.

Saath, K. C. de O. \& Fachinello, A. L. (2018). Crescimento da demanda mundial de alimentos e restrições do fator terra no Brasil. Revista de Economia e Sociologia Rural, Piracicaba, $56(2), 195-212$.

Sbissa, A. P., Ribeiro, N. \& Sbissa, A. S. (2017). A relação entre a satisfação no trabalho com a saúde do trabalhador: um estudo em uma cooperativa de crédito. Arquivos Catarinense de Medicina, 46(3), 147-159.

Siqueira, M. M. M. (2008). Medidas do comportamento organizacional: satisfação no trabalho. São Paulo: Artmed.

Sink, D. S. \& Tuttle, T. C (1993). Planejamento e medição para a performance. Rio de Janeiro: Qualitymark.

Silva, G, A, R. (2016). Satisfação no trabalho, mais que uma questão salárial: um estudo entre os funcionários do supermercado rede mais Venâncio na cidade de Currais Novos/RN. Trabalho de conclusão de curso Universidade Federal do Rio Grande do Norte - UFRN, Brasil.

Sirotenco, M. A. P. (2007). Análise do nível de satisfação e insatisfação dos funcionários das lojas americanas situadas no centro de Florianópolis. Trabalho de conclusão de curso, Centro de educação de Biguaçu, Universidade do Vale do Itajaí, Biguaçu, SC, Brasil.

Spector, P. E. (2003). Psicologia nas organizações. São Paulo: Saraiva, 2003.

Stefano, S. R., Campos, E. A. R. de \& Crist, E. (2014). Práticas de benefícios sociais nas organizações: desafios na gestão de pessoas. Revista Cesumar: Ciências Humanas e Sociais Aplicadas, 19(1), 65-88.

Steinhardt, M. A., Dolbier, C. L. \& Gottlieb, N. H. (2003). The Relationship between hardiness, supervisor support, group cohesion, and job stress as predictors of job satisfaction. American Journal of Health Promotion, 17, 382-389.

Tamayo, A. (2000). Prioridades axiológicas e satisfação no trabalho. São Paulo. Revista de Administração, 35. (2), 37-47.

Tribunal Superior de Trabalho (2021). Jornada de trabalho. Disponível em: $<$ https://www.tst.jus.br/jornada-de-trabalho>. Acesso em: 20 jun. 2021. 
Wagner, J. A. \& Hollenbeck, J. R. (1999). Comportamento organizacional: criando vantagem competitiva. São Paulo: Saraiva.

Wood Júnior, T. \& Picarelli Filho, V. (2004). Remuneração e Carreira por Habilidades e por Competências: Preparando a Organização para a Era das Empresas de Conhecimento Intensivo. $3^{\text {a }}$ Ed. São Paulo: Atlas.

World health organization. (1995). Global strategy on occupational health for all: the way to health at work. Disponível em: http://www.who.int/occupational_ health/publications/globstrategy/en/print.htm>. Acesso em: 22 Jan. 2021.

Yin, R. K. (2015). Estudo de caso: planejamento e métodos. 5. ed. Porto Alegre: Bookman.

Submetido em: 17.02 .2021

Aceito em: $\quad 06.09 .2021$ 